\title{
LA FORMA DE LA ESCRITURA EN LA OBRA DE SAMUEL BECKETT (O ¿QUÉ PODEMOS INTERPRETAR?)
}

\author{
Max Hidalgo Nácher \\ Universitat de Barcelona
}

El que las discusiones en torno a obras literarias suelan concluir dirimiendo cuestiones de significado parecería sugerir que el crítico literario o el historiador de la literatura se ha sentido, desde siempre, más a gusto ante la pregunta: "¿Qué dice ese texto? ¿Qué significa?" que ante esta otra: “¿Qué hace ese texto? ¿Qué podría hacer?”. Bastará con hojear unos pocos volúmenes de cualquier biblioteca para darse cuenta de ello: cuando el discurso cae sobre lo escrito tiende a convertirlo, sin mayores mediaciones, en otro objeto del discurso.

La humilde pretensión de esta contribución es recordar que, antes de que eso sea objeto alguno, constituye un artefacto, y que sólo a condición de respetar dicha especificidad eso puede hacer algo por su cuenta. Contra la reducción de lo escrito a documento, a testimonio de otra cosa, nos proponemos traer a primer plano su uso o acción (la cual implica la competencia técnica de un saber hacer práctico). Si para cierta ciencia social lo escrito representa a una cierta sociedad o literatura, nuestro acercamiento tratará de mostrar cómo lo propiamente poético -no pudiendo representar nada-se limita en el mejor de los casos a hacer algo.

\section{I}

En ese sentido, cabe recordar que la palabra interpretación tiene -en la vida corriente y en cl habla- al menos dos sentidos, los cuales aparecen recogidos por la Real Academia, de modo que en su diccionario aparece lo que sigue como primera acepción: «Explicar o declarar el sentido de algo, y principalmente el de un texto». Este primer sentido de la interpretación se emparentaría, pues, con la noción de "exégesis". Y, sin embargo, "interpretación" se utiliza también de otro modo, como cuando se dice que se interpreta un baile, un papel, una partitura, una pieza musical o -por qué no- un texto. Interpretación, por tanto, como ejecución (recogido en las $6^{\mathrm{a}}$ y $7^{\mathrm{a}}$ acepción de la Academia): «Ejecutar una pieza musical mediante canto o instrumentos» y «Ejecutar un baile con propósito artístico y siguiendo pautas coreográficas». 


\section{LA FORMA DE LA ESCRITURA EN LA OBRA DE SAMUEL BECKETT}

Ahora bien, lo que en esa disparidad de sentidos suele olvidarse es que, en artes temporales como las del lenguaje, para llevar a cabo cualquier "interpretación" semántica es necesaria una "ejecución" previa. De hecho, en lo que respecta a las artes del lenguaje, la mentada dicotomía remitiría, no ya a una cierta especificidad del lado del objeto (que permitiría diferenciar a los textos entre textos para ser comprendidos y textos para ser ejecutados), sino a la especificidad de una práctica de lectura de la cual, sin embargo, sucle hacerse abstracción.

\section{II}

La obra de Samucl Beckett nos permite ilustrar estas relaciones entre el hacer y cl decir, entre la forma de la escritura y su significado, entre lo poético y el orden del discurso. Pues, si algo muestra su recepción, es una insistencia generalizada en tratar de reducir aquellos textos a discurso: en tratar de reducirlos a significado.

Así, para una cierta interpretación dominante hasta hace poco (fruto de una lectura de posguerra comandada por una cierta filosofía existencial' ${ }^{1}$ ), Beckett sería el escritor del absurdo; y, su obra, la representante de la angustia, la soledad, el sufrimiento y la incomunicación propias de la condición humana. Para otra aproximación prestigiosa, ligada a la prosa y bajo influencia de Maurice Blanchot, la obra de Beckett sería el lugar en el que hablaría el vacío del lenguaje y su errancia sin fin. Beckett sería, así, el escritor de «la parole neutre», quien "pour écrire, est tombé dans l'absence de temps, là où il lui faut mourir d'une mort sans fin» (Maurice Blanchot, 1971: 124-125), y el esfuerzo crítico consistiría -en lo que se ha venido a calificar como una crítica mimética (Bruno Clément, 2004: 220-221)-en producir una especie de equivalente crítico de la propia obra.

Y con este somero repaso hemos dado cuenta de los dos discursos principales que han cuasi monopolizado la obra de Beckett hasta hace bien poco, abriendo en ella una falla: cl que, ligado a Martin Esslin, hablaba del dramaturgo del absurdo, y el otro que, por la intermediación de Maurice Blanchot, hablaba del prosista de la palabra neutra (Maurice Blanchot, 1959: 286-289). Es este último quien, tras afirmar que «il n'y a pas d'oeuvre chez. Beckett», debe hacer notar: «Mis à part les textes de théâtre, écrits quand il veut avoir un double, un compagnon de solitude» (Maurice Blanchot, 1990 : 636). Y Ludovic Janvier añade en el mismo sentido: «Il me semble que le personnage de théâtre, puisqu'il cherche à ne pas se trouver, vibre moins près de l'être, moins près du tremblement central, moins près de la peine» (VV.AA., 1990 : 50). En efecto, dada la posición de la que se parte, el teatro de Beckett no puede ser para dichos autores sino algo marginal.

De ese modo tenemos, por un lado, un discurso de la verdad del ser que -centrándose en la obra en prosa- se desentendía del teatro y, por el otro, un discurso del absurdo que dejaba de lado

\footnotetext{
1.- En ese sentido, uno de los principales escollos de la interpretación es la explicación del texto por la remisión (generalmente unilateral) a un autor o a una época. Éste es el caso de Emmanuel Jacquart, artífice de la expresión "théâtre de dérision", quien trata de explicar la obra de Beckett por su época y por su temperamento. De ese modo, el texto sería así, una vez más, explicado por la pequeña y la gran historia: reducido a cllas. Los tres grandes temas del "théâtre de dérision"-la soledad, el sufrimiento y el absurdo de la condición humana- serían aplicables a la obra de Beckett. De ese modo, Jacquart confunde el discurso que cae sobre Beckett con la obra de Beckett mismo: «De même que dans les années quarante on parlait volontiers d'authenticité et d'engagement, de même dans les années cinquante on est intarissable sur la solitude, la souffrance, et l'absurdité de la condition humaine -mots d'ordre d'ailleurs hérités de l'Existentialisme. L'engouement, le néo-romantisme et la publicité littéraire ont certes contribué à la vogue de ces thèmes. Il n'en demeure pas moins que ces derniers coïncidaient avec une réalité vivement sentie, indubitablement inscrite dans l'époque. C'est pourquoi on les retrouve à la fois chez Adamov, Ionesco et Beckett, nonobstant les différences individuelles [...]. La solitude, la souffrance, le sentiment d'être livré à un monde absurde, s'expliquent aussi par un certain type de tempérament, par une prédisposition à l'angoisse et peut-être même à la névrose» (Emmanuel Jacquart, 1974: 77).
} 


\section{MAX HIDALGO NÁCHER}

la novela. Si el primer discurso cuajó en un ámbito preferentemente académico y francés ${ }^{2}$, el segundo discurso caló de modo más hondo y duradero entre el gran público, de modo que muchas de las ideas asociadas al mismo se mantienen, hasta cierto punto $-\mathrm{y}$ por lo menos entre el gran público-, aún vigentes en España. Así, en un artículo reciente, Manuel Vicent se permitía escribir en Babelia, suplemento literario del diario El País, apuntando al centro del tópico: «Beckett sólo tenía dos certezas: que había nacido y que tenía que morir. La vida es un baile absurdo que sucede entre esos dos silencios, y él se veía impulsado a contárselo a alguien» (Manuel Vicent, 2006).

Estas interpretaciones, siendo interesantes en tanto que se inscriben en una sarta de problemas a los que interrogan, corren, sin embargo, el riesgo de ocultar -sobre todo a partir de su vulgarización- la especificidad de dichos textos, es decir, aquello que los separa de, por cjemplo, los discursos que hablan de ellos. Y no sólo eso, sino que tanto unos discursos como los otros se han revelado incapaces de dar cuenta de forma coherente del conjunto de la obra beckettiana. Pues si lleváramos a cabo un análisis diacrónico de la obra beckettiana constataríamos las relaciones de contrapunto, confusión y complemento que se dan entre su prosa y su teatro. En ese sentido, no sería difícil mostrar el papel que debió de jugar el teatro (basado, en Beckett, en juegos de repeticiones) en la superación del callejón sin salida al que le había abocado la escritura de L'Innommable. Sorprende, así, que la obra de Beckett raramente haya recibido un tratamiento unitario y que, aún hoy en día, tengamos a un Beckett doble o triplemente bifronte. Las oposiciones "prosa/teatro", "crítica francófona/crítica anglófona", "lectura blanchotiana/lectura del absurdo"... han ido así diluyéndose desde aquellos primeros acercamientos sin, por ello, haberlo hecho efectivamente aún del todo.

\section{III}

A pesar de la disparidad de perspectivas, si algo une a dichas aproximaciones es el hecho de que ambas se preguntan por qué es la obra de Beckett más que por cómo está hecha. Y el cómo de esas obras es importante; importante, por ejemplo, para dirimir la cuestión, que ha dado tanto que hablar, de la comicidad de los textos beckettianos. Éstos, ¿son cómicos o son más bien patéticos? ¿Representan acaso la tragedia de no poder llegar a la tragedia? Y, en ese caso, esa tragedia, ¿sería entonces cómica?, ¿sería patética? Opiniones, las hay para todos los gustos. En attendant Godot fue interpretado patéticamente en su momento en clave existencial (tal es el famoso "malentendido" de Godot: la superposición de unos discursos que, aparentemente, daban razón de la obra); ahora bien, unos años más tarde, Roland Barthes veía que Godot ya sólo podía hacer reír a carcajadas ${ }^{3}$. En cuanto a Martin Esslin, percibía más bien la tensión entre un contenido presuntamente "sombrío" y una forma presuntamente "cómica", decantándose por la preponderancia de lo segundo". Ahora bien, el problema que presentan tales discusiones no es tanto la inadecuación de las respuestas como la esterilidad de una pregunta mal planteada desde su misma raíz, derivada, en última instancia, del mismo olvido del que venimos hablando. De ese modo, para poner en duda la presunta comicidad o patetismo de los textos beckettianos, no nos haría falta ir rebatiendo una por una todas las opiniones lanzadas al respecto, sino que nos bastaría

2.- Como escribe Pascale Casanova desde su contexto francófono, «dès les années 50, le discours blanchotien est devenu le seul commentaire autorisé» sobre Beckett (1997: 8).

3.- Roland Barthes hacía notar en un artículo que En attendant Godot se había transformado con el tiempo: de obra de vanguardia había pasado a obra para todos los públicos. Y, mientras que antaño era patética, ahora haría reír «à visage découvert». «Des milliers d'hommes ont pris Godot en main, l'ont débarrassé de sa pellicule intellectualiste (à vrai dire apposée surtout par la critique), et quelle que soit l'interprétation qu'ils lui donnent, ils se retrouvent unis dans un acte collectif: le rire» (2002: 88).

4.- « $\Lambda \mathrm{s}$ the incomprensibility of the motives, and the often unexplained and mysterious nature of the character's actions in the Theatre of the Absurd effectively prevent identification, such theatre is a comic theatre in spite of the fact that its subject-matter is sombre, violent, and bitter» (Martin Esslin, 1976: 401). 


\section{LA FORMA DE LA ESCRITURA EN LA OBRA DE SAMUEL BECKETT}

con acercamos a la práctica teatral para ver a las claras cómo, desde ella, este tipo de debates pierden suelo. Así, no es ya tanto que la comicidad y el patetismo sean puestos en tela de juicio constantemente por la obra sino que, más bien, por lo común no pertenecen propiamente a ésta, no pudiendo ser elucidadas sino a través de la interpretación propiamente teatral y, subsidiariamente, de los humores del público en cuestión. De hecho, lo cómico en Beckett, tanto como lo patético, no son, por lo común, sino efectos de una interpretación determinada.

Ello, por otra parte, no parecería reclamar más prueba que el testimonio empírico de aquellos que rieron y lloraron ante dichas representaciones. En ese sentido, los materiales reunidos en la Revue d'Esthétique (VV. AA., 1990) por actores y directores de teatro (así como el número 15 de la revista Samuel Beckett Today/Aujourd'hui ${ }^{5}$ ) dan testimonio suficiente del funcionamiento del teatro beckettiano (y, a través de él, del teatro en general). En relación a ello, se sabe que el tempo pucde ser, en ocasiones, un criterio suficiente para hacer que una obra se decante ora hacia la comicidad, ora hacia el patetismo. Con ello, no deja de ser gracioso el hecho de que, de ese modo, el debate filosófico que no tiene en cuenta la dimensión rítmica y formal pueda convertirse en ocasiones en un mero títere de la técnica en cuestión, pues dichas características a partir de las que tanto se ha especulado serían en gran medida fruto de la ejecución. El director de teatro Walter Asmus da testimonio de ello con motivo de una puesta en escena de En attendant Godot: «Le comique naissait par le rythme et le minutage. Le comique venait de lui-même, sans qu'on en parle. Un minutage très précis. Beckett disait: Ils sont épuisés: plus lentement, parlez plus bas. Et cela devenait pathétique» (VV. AA., 1990: 352). Eso era en 1984. Tal vez Beckett había reparado en ello un lustro antes, durante la grabación de Quad, pieza para televisión en la que cuatro figuras de diferentes colores - y acompañadas de percusiones- se deslizan rápidamente en un cuadrado en una suerte de danza sin fin. El director de la pieza, viendo muy bellas «las imágenes en negro y blanco retransmitidas por la pantalla de control en la cabina de producción», decide mostrárselas a Beckett quien, fascinado, «pregunta si podrían grabar al día siguiente una nueva versión, a menor velocidad y en blanco y negro». Suprimen los acelerados golpes de la percusión, visten de blanco a las figuras y las hacen avanzar muy lentamente: acaba de alumbrarse Quad II. Encantado, Beckett exclama que la pieza tiene lugar «diez mil años después» (James Knowlson, 1996: 592593) de la primera.

Así, y al menos en este caso, todo sería una cuestión de tempo; por eso Beckett ponía tanto énfasis, en su labor de director, en que los tempi estuvieran bien medidos y regulados, hasta el extremo de haber llevado alguna vez un metrónomo a los ensayos.

\section{IV}

Ahora bien, más allá del patetismo o de la comicidad, del teatro del absurdo o del ser del lenguaje, es evidente que la obra de Beckett ha dado mucho que hablar. Así, de sus obras y personajes se han dado interpretaciones para todos los gustos: unos vieron Esperando a Godot como una obra realista; otros, como anti-teatro. Unos lo concibieron como un drama cristiano; otros, un drama anti-cristiano. Respecto al propio Godot, a éste se le ha hecho ser: un Dios (God); un Dios de farsa (de modo Godot sería a God, como Charlot a Charles o Pierrot a Pierre); un ciclista veterano del que se decía que siempre llegaba tarde (Godeau); el más allá; la propia espera... y tantas otras cosas más (Pérez Navarro, 1976: 223-234). De ese modo, cl "enigma de Godot" parece que tendría que ser puesto en relación, no ya con quién fuera Godot, sino con la cantidad de interpretaciones que ha propiciado. A su vez, el textito de Bing ha representado (para un grupo de profesores universitarios reunidos en la Universidad de Birmingham) un fusilamiento, un hombre en la ducha o la agonía de Cristo en la tumba (David Lodge, 1968: 85-89); representaciones que, si difícilmente casan entre sí, más difícilmente lo hacen con el texto en cuestión.

5.- Marius Buning et al., 2005. 


\section{MAX HIDALGO NÁCHER}

De donde resulta que de sus obras y personajes se han dado interpretaciones para todos los gustos. Puestas en un mismo saco, todas ellas suman demasiadas interpretaciones para unos personajes que, como aquellos de Fin de partie, reían ante la sola idea de poder estar significando algo:

HAMM : On n'est pas en train de... de... signifier quelque chose ?

CLOV : Signifier ? Nous, signifier ! (Rire bref.) Ah elle est bonne !6

Dicho lo cual, la prolijidad de interpretaciones nos muestra algo, a saber, que dichas obras nos permiten disparar las asociaciones -a veces hasta el disparate, como cuando se dijo que Godot cra nada más y nada menos que... Charles de Gaulle. Y si ello es posible, se debe, entre otros motivos, a su forma, a su construcción, basada en un énfasis desmedido en la repetición (que se da en un comienzo en su teatro y, tras el callejón sin salida de L'Innommable, en cl conjunto de su obra); en un énfasis en eso que Jakobson llamaba "la función poética" y que nosotros llamaremos aquí simple y llanamente "ritmo".

Al descuidar el ritmo, los enfoques antes mentados, si bien no serían ciegos, serían, para desgracia de los textos de los que tratan, fundamentalmente sordos. Beckett no puede ser ni el autor del absurdo que se le ha hecho ser ni el de la verdad del ser, ni el de lo cómico ni el de lo patético. Ante dichas afirmaciones, sólo podríamos alegar que sus textos permiten hacer "muchas cosas". Pues si lo poético es algo (algo diferente a su significado o al habla de los negocios de la vida), se debe justamente a ese juego que establece con el pasar: no con el significado, sino con el sentido (la acción) gramatical y su puesta a bailar rítmicamente. La interpretación tiende a borrar eso que pasaba para hacerse una idea del conjunto, reduciéndolo en general a significado. Pero ya se ve que los textos de Beckett, si podían significar muchas cosas, no significaban nada. En ese sentido, ya Watt (1942-1945) se cerraba con la siguiente frase: "No symbols where none intended» (Samuel Beckett, 1970: 255). Por el resto, la famosa frase de Breton que suspende la interpretación («S’il avait voulu dire ça, monsieur, il l'aurait dit») ya fue declinada en diferentes ocasiones por el propio Beckett. Así, preguntado por Poz7.o, personaje de En attendand Godot, respondía: «Too tired to give satisfaction I told him that all I knew about Pozzo was in the text, that if I had known more I would have put it in the text, and that this was true also of the other characters»?

\section{VI}

Pero, ¿por qué esa tozudez? En lo que a mí concierne, sólo puedo entenderla como la respuesta insistente y repetida a una misma sordera. La interpretación trata, por lo general, de "traducir" lo "dicho" en el texto; y el escritor, que no quiere simplemente ser entendido o comprendido, sino oído y escuchado, repite al sordo, una y otra vez, que deje de hacerse ideas y que escuche; pero -por lo visto- éste seguiría sin escuchar. Así, mejor que tratar de discernir qué ha dicho un escrito o poema (reduciéndolo escolásticamente a discurso como a Beckett se le redujo a una filosofía existencial que le quedaba más que estrecha), sería tratar de dar cuenta de lo que éste hace, de lo hecho en él.

De ese modo, la singularidad de lo poético (su singularidad técnica y formal) parecería concedernos un punto de apoyo para emprender el análisis de los textos. Ahora bien, los lectores que no tengan acceso ni al francés ni al inglés tendrán un problema añadido para escucharlos, a saber, que éstos les llegarán mediados por las traducciones.

Y lo que ocurre con las traducciones es, de hecho, análogo a lo que pasa con las interpretaciones. Pues, si bien es posible una traducción neutra (diríamos objetivizante), nunca será posible una

6.- Samuel Beckett, 2001: 49.

7.- Samuel Beckett a Barney Rosset, 18 de octubre de 1954 (citado en James Knowlson, 1996: 372). 


\section{LA FORMA DE LA ESCRITURA EN LA OBRA DE SAMUEL BECKETT}

traducción neutral. De ese modo, como recuerda Roman Jakobson, toda transposición ha de ser creativa:

Seule est possible la transposition créatrice: transposition à l'intéricur d'une langue -d'une forme poétique à une autre-, transposition d'une langue à une autre, ou, finalement, transposition intersémiotique -d'un système de signes à un autre, par exemple de l'art du langage à la musique, à la danse, au cinéma ou à la peinturc. / S'il nous fallait traduire en français la formule traditionnelle Traduttore, traditore, par "le traducteur est un traître", nous priverions l'épigramme italienne de sa valeur paronomastique. D'où une attitude cognitive qui nous obligerait à changer cet aphorisme en une proposition plus explicite, et à répondre aux questions: traducteur de quels messages? traître à quelles valeures? ${ }^{8}$

Una vez planteada la cuestión en dichos términos, nos cabe preguntarnos: ¿qué traduce el traductor?, ¿qué es lo que trata de transportar de un lado al otro?, ¿lo que el texto hace o lo que éste dice? Toda traducción que se precie ha de ser-por su cuenta y riesgo- ella también escritura, asumiendo la parte productiva de cualquier transposición. De otro modo, oculta su objeto al tiempo que se condena al fracaso. Y no hará falta que indique que la traducción, actual y mayoritariamente, vive del olvido de la singularidad de lo poético. Henri Meschonnic lo ha hecho notar: si hay artefactos que duran y duran -raramente lo hacen sus traducciones (Henri Meschonnic, 1999: 22). En efecto, las malas traducciones borrarían la tan frágil singularidad de lo poético, sustituyéndola por una información sobre sus presuntos contenidos. De ese modo, la traducción de lo poético nos revelaría, por contraste (y, por así decir, monstruosamente), lo no poético de la poesía, traduciendo lo que las palabras dicen, pero no lo que éstas hacen.

A Beckett -decíamos- se le lee en España a través de traducciones, las cuales, muchas veces, no pueden o no saben respetar esa fina trama que sostiene sus textos. Escuchemos, hagamos sonar a continuación un fragmento de la pieza de teatro Footfalls:

May: Were you asleep?

Woman's voice: Deep asleep. (Pause.) I heard you in my deep sleep. (Pause.) There is no sleep so deep I would not hear you there. (Pause. $M$ resumes pacing. Four lengths. After first length, synchonous with steps.) One two three four five six seven eight nine Wheel one two three four five six seven eight nine whell. (Free.) Will you not try to snatch a little sleep? ( $M$ halts facinf front at $R$. Pause. $)^{9}$

Y, a continuación, la traducción al castellano de la misma, a cargo de Jenaro Talens:

May: ¿Dormías?

Voz de mujer: Profundamente. Te he oído en mi sueño profundo. No hay sueño lo suficientemente profundo como para que me impida oírte. (Pausa. M inicia de nuevo su marcha. Cuatro recorridos. Después del primero, sincronización con los pasos.) Uno dos tres cuatro cinco seis siete hop uno dos tres cuatro cinco seis siete hop. (De forma espontánea.) ¿No quieres echar una cabezadita? ( $M$ se detiene frente a $D$. Pausa. $)^{10}$

Sin entrar en las dificultades de traducción (nunca, por cierto, insalvables), las diferencias saltan a la vista: los juegos fonéticos desaparecen; también los juegos rítmicos. El predominio de los troqueos de la versión inglesa (ligado al ritmo de los pasos) es sustituido por un ritmo más suelto y descuidado en su versión castellana. La repetición por cinco veces de las palabras sleep/ asleep da paso a la vuelta en tan sólo dos ocasiones de la palabra sueño, la cual no resuena con ninguna otra. La textura sonora del primero es también borrada: la traducción no presenta ni rimas ni juegos sonoros. Por último, y dado el ritmo yambo-trocaico que lo teje, el primer texto podría recitarse - sin mayores dificultades-a compás, lo que en la versión castellana de Jenaro Talens no podría llevarse a cabo sino con gran violencia por parte del recitante.

8.- Roman Jakobson, 1970: 86.

9.- Samuel Beckett, 2006: 401.

10.- Samuel Beckett, Pavesas, 2000: 228. 


\section{MAX HIDALGO NÁCHER}

Entre la versión castellana y el original inglés tenemos la versión francesa del propio Beckett, la cual -sin llegar a recrear la densidad rítmica de Footfalls-se aproxima mucho a ella, pudiendo igualmente recitarse a compás. Lo terrible del caso es que la consistencia de dichas obras descansa toda ella en esos pequeños "detalles" que tienen que ir, por así decirlo, puntuando la obra junto con los pasos.

No estaría de más recordar, no sólo a los actores, sino a los traductores de esas obras -y a los traductores en general- una frase de May, personaje de Footfalls: «The motion alone is not enough, I must hear the feet, however faint they fall» ${ }^{11}$. Pues es en ese golpear de pies y pasos, en esa vuelta de los movimientos, en el sonido de las dicciones donde se sostiene la picza. No en vano, Beckett definirá el teatro como una «forma en movimiento» (Shimon Levy, 1990: 26). «Parece que los directores de escena no tienen sentido de la forma que encierra el movimiento», dice Beckett, «de la forma que se encuentra, por ejemplo, en la repetición de un tema musical. Si en un texto se repiten ciertas acciones, la primera vez ya hay que presentarlas de manera inusitada para que el público pueda reconocerlas cuando se repitan». De ese modo, Bekett dice que, del teatro, le interesa sobre todo «el estrato dinámico que yace bajo la palabra escrita» ${ }^{12}$. Y, a fin de cuentas, ¿no es eso el ritmo?

El éxito o el fracaso de la pieza está ahí: en saberla interpretar. En los ensayos de una de las representaciones de Footfalls, Beckett trabaja con su actriz Billie Whitelaw sobre el más ínfimo detalle, el cual era, a su juicio, el más importante de la obra (VV. AA., 1990: 334): los pasos. En efecto, ello ha de sostenerse o fracasar en esos nueve pasos de la protagonista, que han de verse y oírse como redundancias, como vueltas de lo mismo en lo diferente. El tejido rítmico que constituye el soporte y fundamento de esas obras ticne así como condición necesaria la precisión en la ejecución, sin la cual todo se desmoronaría: «Sam n'essaie pas d'expliquer ce que la pièce veut dire, la partie invisible de la pièce, il dit qu'il faut faire cela et cela, il faut le faire avec son corps, sa voix, ses lèvres» (VV. AA., 1990: 345).

\section{VII}

Si gran parte de las interpretaciones de la obra de Beckett muestran el olvido de la dimensión formal (y, en su extremo, de la rítmica, la cual es condición de posibilidad y límite de la misma), aquí se trataba simplemente de recordarla. Pues quien se queda con el decir de Beckett todavía se está perdiendo mucha cosa. Haciendo abstracción tanto de la forma como de la interpretación, no podrá menos que tomar lo dado a contrapié. De ese modo, toda interpretación exegética o hermenéutica, antes de reposar en sí, tendrá que vérselas y que prestar oído a los textos. Se propone, de ese modo, una abertura de la interpretación en un sentido no directamente semántico, sino más bien "musical" y, en cualquier caso, tangible y corporal; abertura por donde se ve que la interpretación se acerca a la crítica y, en su límite, a la lectura -único lugar desde el cual, si es que la interpretación quiere seguir siendo alguna cosa, ésta podría hacer algo. Si la lectura, como ya viera Mallarmé, es antes que nada una práctica ${ }^{13}$, en tanto que práctica, tendrá que ser la práctica de un cuerpo. A quienes se olvidan de ello, podría recordárseles aquello que Mallarmé ya replicara a quienes tachaban su poesía de incomprensible: «Je préfère, devant l'agression, rétorquer que des contemporains ne savent pas lire» (Stéphane Mallarmé, 1945: 386).

De ese modo, la primacía del discurso en general (y del discurso filosófico en particular) sobre el resto de prácticas (sean o no discursivas) debe ser puesta en duda. Los escritores no "aplicarían" ideas filosóficas (no sería eso lo que podría sostener sus obras en ningún caso); en el mejor de los casos, las pondrían a funcionar a través del trabajo formal, no ya presentándolas como enunciados, sino introyectándolas en la propia enunciación.

11.- Footfalls (en Samuel Beckett, 2006: 401).

12.- Charles Marowitz, en Encore, ${ }^{\circ}$ 9, Londres, marzo-abril, 1962 (citado en Klaus Birkenhauer, 1976: 158).

13.- «Lire - / Cette pratique» (Stéphane Mallarmé, 1945: 387). 
De ese modo, de lo que se trataba aquí era, no ya de censurar las interpretaciones, sino, más bien, de llamar la atención sobre su suelo, el cual, no siendo siempre tan firme como se piensa, suele abandonarse, no obstante, demasiado pronto. Ya lo recordaba Roman Jakobson: «Nommer le sens d'unc ouvre individuelle, on l'a vu, ne fait pas partie des tâches de la poétique, pas plus que l'explication de son effet esthétique; mais la description exacte des procédés poétiques mis en cuvre permet d'invalider les interprétations abusives» (Roman Jakobson, 1970: 349).

Dichos procedimientos deberían ser puestos en primer plano, pues el "significado" de las obras -en tanto que las sigamos considerando como artefactos- sólo puede derivarse de las mismas. De ese modo, el desfondamiento del discurso o, al menos, su puesta en suspenso, es, quizás, condición necesaria e irrenunciable para permitir a los textos no ya que digan (haciendo posibles las interpretaciones históricas, sociológicas, biográficas...), sino que hagan lo que puedan.

Todo ello, en fin, creo que vale también -si se quiere, en un nivel diferente- para el trabajo académico. Tiene sentido, pues, que nos preguntemos qué hacemos aquí. ¿Qué nos atrae en los textos? ¿Cómo los leemos? ¿Qué vemos o que oímos en ellos? ¿Qué dejamos de lado? ¿Cómo los trasponemos, traducimos, interpretamos? Y, en todo ello, ¿qué es lo que hace que nuestro objeto de estudio no sea directamente y sin mediaciones el objeto de estudio tradicional de disciplinas como la Historia o la Filosofía?

\section{BIBLIOGRAFÍA}

\section{Samuel Beckett}

Beckett, Samuel (1970), Watt, Germany, Calder \& Boyars.

Beckett, Samuel (2001), Fin de partie, France, Éditions de Minuit.

Beckett, Samuel (2006), The complete dramatic works, England, Faber and Faber.

Beckett, Samuel (2000), Pavesas, cdición de Jenaro Talens, Tusquets, $2^{\text {a }}$ edición.

\section{O'TROS}

Birkenhauer, Klaus (1976), Samuel Beckett, Madrid, Alianza editorial.

Barthes, Roland (2002), “Godot adulte”, en Écrits sur le théâtre, Points, Éditions du Seuil, pp. 87-90.

Blanchot, Maurice (1990), "Oh tout finir", Critique, "Samuel Beckett", n 519-520, Paris, aoûtseptembre, pp. 635-637.

— (1971), "Le vide et l'appel de l'oeuvre", en Les critiques de notre temps et Beckett, Paris, Garnier, 1971.

__ (1959), "Où maintenant? Qui maintenant?", en Le livre à venir, "Folio", Gallimard, 1990.

Buning, Marius et al., eds. (2005), Samuel Beckett Today / Aujourd'hui, n 15, "Historicising Beckett / Issues of Performance. Beckett dans l'histoire / En jouant Beckett", Amsterdam/New York, Rodopi.

Casanova, Pascale (1997), Beckett l'abstracteur (anatomie d'une révolution littéraire), Mayenne, Seuil.

Clément, Bruno (2004), "Ce que les philosophes font avec Samuel Beckett", en Anthony Uhlmann, Sjef Houppermans, Bruno Clément, eds., Samuel Beckett Today/Aujourd'hui, no 14, "After Beckett/D'après Beckett”, Amsterdam/New York, Rodopi, pp. 219-236.

Esslin, Martin (1976), The theatre of the absurd, London, Penguin Books. 


\section{MAX HIDALGO NÁCHER}

Jacquart, Emmanuel (1974), Le théâtre de dérision. Beckett, Ionesco, Adamov, France, Idées/ Gallimard.

Jakobson, Roman (1970), Essais de linguistique générale, Points, Éditions de Minuit.

Knowlson, James (1996), Damned to Fame. The Life of Samuel Beckett, USA, Simon \& Schuster.

Levy, Shimon (1990), Samuel Beckett's Self-referential Drama. The Three I's, New York, St. Martin's Press.

Lodge, David (1968), «Some Ping Understood», Encounter, Vol. XXX, n².

Mallarmé, Stéphane (1945), Oeuvres complètes, Paris, Gallimard.

Meschonnic, Henri (1999), Poétique du traduire, France, Verdicr.

Pérez Navarro, Francisco (1976), Galería de moribundos. Introducción a las novelas y al teatro de Samuel Beckett, Barcelona, Grijalbo.

Vicent, Manuel (2006), "El caos entre dos silencios", Babelia (El País), 20-8-2006.

VV. AA. (1990), Revue d'Esthétique. Samuel Beckett, nº hors série, Jean Michel Place. 